\title{
Hyperhomocysteinemia and vascular access thrombosis in hemodialysis patients: a retrospective study
}

This article was published in the following Dove Press journal:

Vascular Health and Risk Management

16 July 2013

Number of times this article has been viewed

\section{Chadi Saifan \\ Elie El-Charabaty \\ Suzanne El-Sayegh}

Staten Island University Hospital, Staten Island, NY, USA
Correspondence: Chadi Saifan Staten Island University Hospital, 475 Seaview Avenue, Staten Island, NY 10305, USA

Tel +I 7182269000

Fax + I 7182268494

Email chadisaifan@hotmail.com
Background: Elevated total plasma homocysteine is an independent risk factor for arterial and venous thrombosis in patients with normal renal function. Patients on hemodialysis have a high prevalence of mild to moderate hyperhomocysteinemia. Conflicting retrospective analyses and prospective studies have been reported regarding the association between total homocysteine levels and hemodialysis vascular thrombosis. The purpose of this retrospective study was to investigate the relationship between hyperhomocysteinemia and vascular access thrombosis (VAT) in patients on hemodialysis.

Methods: One hundred and twenty-five patients undergoing dialysis were selected as subjects. The experimental group participants were identified as those having one or more VAT during the previous 13 months and the control group participants had no access thrombosis during the same period. Additional subgroup analysis included the presence of hypertension, diabetes, low-density lipoprotein levels, sex, and use of aspirin.

Results: No statistically significant difference was found in total homocysteine levels between the two groups $(P=0.27)$. No association was found between VAT and sex $(P=0.09)$, VAT and hypertension $(P=0.96)$, VAT and diabetes $(P=0.49)$, nor VAT and low-density lipoprotein level $(P=0.04)$. A lower rate of VAT was associated with aspirin intake $(P=0.04)$.

Conclusion: This study did not demonstrate a relationship between total homocysteine concentrations and risk of VAT in patients with end-stage renal disease on hemodialysis. There were no significant differences in the number of VAT across additional variables of sex and previous morbidity. Aspirin intake was associated with a lower incidence of VAT.

Keywords: hyperhomocysteinemia, vascular access thrombosis, hemodialysis

\section{Introduction}

Vascular access failure is a major cause of morbidity and mortality in hemodialysis patients. ${ }^{1}$ Little is understood about the risk factors associated with vascular access thrombosis (VAT). Currently, placement of a synthetic graft and central venous catheter rather than a native arteriovenous fistula represents the better defined risk factor for vascular access failure. ${ }^{2}$ Other risk factors identified in single studies include location of the graft, time of use of graft after surgical creation, diabetes, age older than 65 years, hypoalbuminemia, elevated lipoprotein-a level, lupus anticoagulant, female sex, elevated low-density lipoprotein (LDL) cholesterol, alterations in genes regulating the coagulation cascade, and stenosis within the graft and draining vein. ${ }^{3-5}$ Hyperhomocysteinemia has been reported as a risk factor for VAT. An elevated total plasma homocysteine level is associated with premature atherosclerosis, adversely affecting the endothelium by damaging cells, inhibiting anticoagulants, enhancing 
procoagulants, and impairing the bioavailability of the vasodilator, nitric oxide. ${ }^{6}$ Hyperhomocysteinemia is an independent risk factor for arterial and venous thrombosis in patients with normal renal function. While there is an excess prevalence of mild to moderate hyperhomocysteinemia in hemodialysis patients, the association with VAT has not been universally confirmed. Conflicting retrospective analysis and prospective studies have been reported regarding the association between total homocysteine levels and hemodialysis vascular thrombosis., ${ }^{3,7-9}$

The purpose of this retrospective study was to determine if a significant association exists between hyperhomocysteinemia, age, sex, previous morbidity (diabetes and hypertension), and hemodialysis access thrombosis.

\section{Materials and methods}

One hundred and twenty-five patients undergoing dialysis were selected as subjects from two different dialysis clinics. Patients with a history of antiphospholipid syndrome or on anticoagulation were excluded from the study. Information was obtained from their medical files and included the following for the past 13 months: number of VAT, age, sex, past medical history, duration of hemodialysis, mean LDL level, mean albumin level, mean ferritin level, and aspirin intake. Each patient included in the study was assigned a number to maintain anonymity of the patient and to preserve confidentiality. The plasma homocysteine level was checked once after obtaining informed consent from the patients. The sample was divided into an experimental (VAT, $\mathrm{n}=53$ ) group and control (no VAT, $\mathrm{n}=72$ ) group. Participants in the experimental group were identified as those having one or more VAT during the previous 13 months (December 2003 to January 2005) and participants in the control group were those with no access thrombosis during the same period. Additional subgroup analysis included: presence of hypertension, diabetes, LDL level, sex, (male versus female), and use of aspirin.

\section{Statistical analysis}

The data were analyzed using the chi-square test for categorical variables and $t$-test for interval data. Statistical significance was set at $P=0.05$. Logistic regression was used to examine the relationship between the model of dependent variables and the outcome variable of VAT.

\section{Results}

No significant difference in total homocysteine levels was found between the VAT group and control group, with mean values being $25.2 \pm 8.38$ and $25.69 \pm 1.66$, respectively $(P=0.27)$. No significant association was found between VAT and hypertension $(P=0.96)$, VAT and diabetes $(P=0.49)$, VAT and LDL level $(P=0.40)$, nor VAT and sex $(P=0.09$, see Table 1$)$. The only variable that contributed to explaining the model was aspirin intake, with a $P$-value of 0.04 when considered with the effect of the other variables removed. Aspirin intake had a relative risk of 0.74 (0.49-1.13). This indicated a reduction in risk for access thrombosis of $26 \%$.

\section{Discussion}

Elevated total homocysteine concentrations are common in patients with end-stage renal disease on hemodialysis. The etiology of high homocysteine levels is not well understood. ${ }^{10}$ In addition to the reduced clearance of plasma homocysteine observed, genetic and dialysis-related factors may be involved. ${ }^{5}$ Hyperhomocysteinemia is a well established risk factor for accelerated atherogenesis and coronary heart disease. It is also associated with recurrent venous thrombosis in patients without end-stage renal disease. ${ }^{11,12}$ However, less clear is the relationship between hyperhomocysteinemia and VAT in patients on hemodialysis (Table 2) which is the most common cause of hospitalization among these patients. ${ }^{7}$ Mallamaci et al reported a clear association between high homocysteine levels and cardiovascular mortality and atherothrombotic events in hemodialysis patients. ${ }^{9}$ In another prospective study of 78 patients, Mallamaci et al found that VAT in dialysis patients is associated with hyperhomocysteinemia. ${ }^{8}$ This association was also observed in studies conducted by Shemin et al, Boushey et al, and Bednarek-Skublewska et al. .,13,14 $^{2}$

However, other studies did not demonstrate this association. Bowden et al showed in both a retrospective study of 114 patients $^{15}$ and in a prospective study of 185 patients $^{16}$ that chronically high homocysteine levels in patients with endstage renal disease were not associated with an increased incidence of VAT. A retrospective Taiwanese study conducted by Chen et al in 196 patients on chronic hemodialysis showed no

Table I Demographic characteristics of study patients

\begin{tabular}{llll}
\hline & VAT, $\mathbf{n}=\mathbf{5 3}$ & No VAT, $\mathbf{n}=\mathbf{7 2}$ & P-value \\
\hline Age, years & $6 \mathrm{I} .30 \pm \mathrm{I} 5.7$ & $62.84 \pm \mathrm{I} 3 . \mathrm{I}$ & 0.55 \\
Sex, M/F & $30 / 23$ & $5 \mathrm{I} / 2 \mathrm{I}$ & 0.09 \\
Homocysteine & $25.2 \pm 8.38$ & $25.69 \pm 166$ & 0.27 \\
level $(\mu \mathrm{mol} / \mathrm{L})$ & & & \\
LDL level & $67.1 \pm 28.42$ & $65.86 \pm 28.14$ & 0.40 \\
Ferritin level $(\mathrm{mg} / \mathrm{dL})$ & $761.5 \pm 435$ & $766 \pm 40 \mathrm{I}$ & 0.47 \\
Hypertension $(\mu \mathrm{mol} / \mathrm{L})$ & $44(83 \%)$ & $60(83.3 \%)$ & 0.96 \\
Diabetes mellitus & $24(60.7 \%)$ & $37(39.3 \%)$ & 0.49 \\
Coronary artery disease & $35(63.6 \%)$ & $20(36.4 \%)$ & 0.22 \\
\hline
\end{tabular}

Abbreviations: LDL, low-density lipoprotein; VAT, vascular access thrombosis. 
Table 2 Summary of previous studies assessing the relationship between homocysteine levels and vascular access thrombosis

\begin{tabular}{|c|c|c|c|}
\hline Study & $\begin{array}{l}\text { Type } \\
\text { of study }\end{array}$ & $\begin{array}{l}\text { Patients } \\
\text { (n) }\end{array}$ & $\begin{array}{l}\text { Association between } \\
\text { total homocysteine } \\
\text { and VAT }\end{array}$ \\
\hline $\begin{array}{l}\text { Bednarek- } \\
\text { Skublewska } \\
\text { et al }{ }^{14}\end{array}$ & Retrospective & 85 & Present \\
\hline Bowden et $\mathrm{al}^{15}$ & Retrospective & 104 & Absent \\
\hline Bowden et a $\left.\right|^{16}$ & Prospective & 185 & Absent \\
\hline Chen et al ${ }^{17}$ & Retrospective & 196 & Absent \\
\hline Hojs et $\mathrm{al}^{18}$ & Cross-sectional & 65 & Absent \\
\hline Mallamaci et $\mathrm{al}^{8}$ & Prospective & 78 & Present \\
\hline Manns et $\mathrm{al}^{3}$ & Cross-sectional & 118 & Absent \\
\hline Shemin et $\mathrm{al}^{7}$ & Prospective & 84 & Present \\
\hline Sirrs et al ${ }^{19}$ & Prospective & 88 & Absent \\
\hline
\end{tabular}

Abbreviation: VAT, vascular access thrombosis.

relationship between homocysteine and VAT. ${ }^{17}$ Manns et al found no association between homocysteine levels or anticardiolipin antibody and VAT in a cross-sectional study involving 118 patients. ${ }^{3}$ Similarly, the studies reported by Hojs et al and Sirrs et al demonstrated no significant relationship between homocysteine levels and VAT. ${ }^{18,19}$

Our retrospective study indicates that the total homocysteine level is not a valid marker for VAT. Additionally, we did not discover any trend towards increased total homocysteine levels and VAT. Hypertension and diabetes are associated with premature vascular disease; however, we did not observe this relationship in our study, which is in agreement with the findings of Bowden et $\mathrm{al}^{15}$ and BednarekSkublewska et al. ${ }^{14}$ Our analysis confirmed the findings of other investigators that the use of antiplatelet agents is associated with a reduced risk of VAT. ${ }^{19-21}$

In summary, we found no association between total homocysteine concentration and VAT in patients on hemodialysis. Because of the complexity of the relationship between homocysteine and vascular access failure, long-term prospective studies with serial measurement of homocysteine levels may better address the direct metabolic implications of elevated total homocysteine in hemodialysis patients.

\section{Disclosure}

The authors report no conflicts of interest in this work.

\section{References}

1. Feldman HI, Held PJ, Hutchinson JT, Stoiber E, Hartigan MF, Berlin JA. Hemodialysis vascular access morbidity in the United States. Kidney Int. 1993;43(5):1091-1096.

2. Choudhury D. Vascular access thrombosis prophylaxis. Semin Dial. 2006;19(4):335-342.
3. Manns BJ, Burgess ED, Parsons HG, Schaefer JP, Hyndman ME, ScottDouglas NW. Hyperhomocysteinemia, anticardiolipin antibody status, and risk for vascular access thrombosis in hemodialysis patients. Kidney Int. 1999;55(1):315-320.

4. Heard KA, Russell TA. Access thrombosis, hospitalization, and hematocrit level in hemodialysis patients. Nephrol Nurs J. 2000;27(6): 607-611.

5. Fukasawa M, Matsushita K, Kamiyama M, et al. The methylenetetrahydrofolate reductase C677T point mutation is a risk factor for vascular access thrombosis in hemodialysis patients. Am J Kidney Dis. 2003;41(3):637-642.

6. Lentz SR. Homocysteine and cardiovascular physiology. In: Carmel R, Jacobsen DW, editors. Homocysteine in Health and Disease. New York, NY: Cambridge University Press; 2001.

7. Shemin D, Lapane KL, Bausserman L, et al. Plasma total homocysteine and hemodialysis access thrombosis: a prospective study. $J \mathrm{Am}$ Soc Nephrol. 1999;10(5):1095-1099.

8. Mallamaci F, Bonanno G, Seminara G, et al. Hyperhomocysteinemia and arteriovenous fistula thrombosis in hemodialysis patients. Am J Kidney Dis. 2005;45(4):702-707.

9. Mallamaci F, Zoccali C, Tripepi G, et al. Hyperhomocysteinemia predicts cardiovascular outcomes in hemodialysis patients. Kidney Int. 2002;61(2):609-614.

10. Suliman ME, Bárány P, Kalantar-Zadeh K, Lindholm B, Stenvinkel P. Homocysteine in uraemia - a puzzling and conflicting story. Nephrol Dial Transplant. 2005;20(1):16-21.

11. Den Heijer M, Blom HJ, Gerrits WB, et al. Is hyperhomocysteinemia a risk factor for recurrent venous thrombosis? Lancet. 1995;345(8954): $882-885$.

12. Fermo I, Vigano' D'Angelo S, Paroni R, Mazzola G, Calori G, D'Angelo A. Prevalence of moderate hyperhomocysteinemia in patients with early-onset venous and arterial occlusive disease. Ann Intern Med. 1995;123(10):747-753.

13. Boushey CJ, Beresford SA, Omenn GS, Motulsky AG. A quantitative assessment of plasma homocysteine as a risk factor for vascular disease. Probable benefits of increasing folic acid intakes. JAMA. 1995;274(13): 1049-1057.

14. Bednarek-Skublewska A, Przywara S, Wronski J, Ksiazek A. Influence of homocysteine on the function of native arteriovenous fistula in hemodialysis patients. Dial Transplant. 2006;35(10).

15. Bowden RG, Wyatt FB, Wilson R. Homocysteine and vascular access thrombosis in end-stage renal disease patients: a retrospective study. J Nephrol. 2002;15(6):666-670.

16. Bowden RG, Wyatt FB, Wilson R, Wilborn C, Gentile M. Homocysteine and vascular access thrombosis in a cohort of end-stage renal disease patients. Ren Fail. 2004;26(6):709-714.

17. Chen TC, Wang IK, Lee CH, et al. Hyperhomocysteinemia and vascular access thrombosis among chronic hemodialysis patients in Taiwan: a retrospective study. Int J Clin Pract. 2006;60(12):1596-1599.

18. Hojs R, Gorenjak M, Ekart R, Dvorsak B, Pecovnik-Balon B. Homocysteine and vascular access thrombosis in hemodialysis patients. Ren Fail. 2002;24(2):215-222.

19. Sirrs S, Duncan L, Djurdjev O, et al. Homocyst(e)ine and vascular access complications in haemodialysis patients: insights into a complex metabolic relationship. Nephrol Dial Transplant. 1999;14(3): 738-743.

20. Goldwasser P, Michel MA, Collier J, et al. Prealbumin and lipoprotein(a) in hemodialysis: relationships with patient and vascular access survival. Am J Kidney Dis. 1993;22(1):215-225.

21. Degoulet P, Legrain M, Réach I, et al. Mortality risk factors in patients treated by chronic hemodialysis. Report of the Diaphane collaborative study. Nephron. 1982;31(2):103-110. 


\section{Publish your work in this journal}

Vascular Health and Risk Management is an international, peerreviewed journal of therapeutics and risk management, focusing on concise rapid reporting of clinical studies on the processes involved in the maintenance of vascular health; the monitoring, prevention and treatment of vascular disease and its sequelae; and the involvement of

metabolic disorders, particularly diabetes. This journal is indexed on PubMed Central and MedLine. The manuscript management system is completely online and includes a very quick and fair peer-review system, which is all easy to use. Visit http://www.dovepress.com/ testimonials.php to read real quotes from published authors.

Submit your manuscript here: http://www.dovepress.com/vascular-health-and-risk-management-journal 